\title{
Sulfolane and di-iso-propanol lean amine blend operating temperature and pressure effect to natural gas sweetening using process simulation
}

\author{
Chukwugozie Jekwu Ejeh $^{1} \cdot$ Goh Prince-Henry Mawufemor ${ }^{1} \cdot$ Annan Ransford ${ }^{1}$
}

Received: 18 October 2019 / Accepted: 11 January 2020 / Published online: 30 January 2020

(c) Springer Nature Switzerland AG 2020

\begin{abstract}
Blending physical and chemical solvents has shown to be promising for removing hydrogen sulfide, carbon dioxide and mercaptan from natural gas effectively. Studies show that using sulfolane and methyl di-ethylene amine blend yields better performance than traditional methods. However, the Shell process depicts that blending sulfolane with di-isopropanol amine significantly minimizes the problem associated with amine re-circulation efficiency observed with the application of sulfolane and methyl di-ethylene amine. This study aimed at investigating the effect of temperature and pressure to the acid gas removal performance of sulfolane and di-iso-propanol lean solvent using Aspen HYSYS software. In addition, the determination of optimum blend ratio was considered. The acid gas composition of the natural gas stream was $16.9 \%$. This is a hypothetical data used to mimic a relatively high acid gas content in a typical raw natural gas feed. During the process simulation, the lean solvent temperature and pressure were varied between 5 and $210^{\circ} \mathrm{C}$, and 20 and 250 bar, respectively, while maintaining the reactant flow rate at $819.5 \mathrm{~kg} / \mathrm{h}$. Findings informs that the optimum blend formulation obtained was $15 \%$ water, $15 \%$ sulfolane and $70 \%$ di-iso-propanol amine at operating temperature and pressure of $50{ }^{\circ} \mathrm{C}$ and 45.5 bar, respectively. At the end of the process, the acid gas composition reduced from 16.9 to $0.26 \%$, with an increase in the methane composition by $16.12 \%$. This was as a result of the reduction in the vapor point of the lean solvent, which significantly contributed to enhancing the contact time and efficiency between the gas feed and lean solvent. Hence, the sales gas specification for natural gas was met at lower operating temperature and pressure below $10^{\circ} \mathrm{C}$ and 25 bar, respectively.
\end{abstract}

Keywords Acid gas removal · Amine treatment $\cdot$ Flow process simulation $\cdot$ Chemical solvent $\cdot$ Physical solvent

\section{Introduction}

Natural gas obtained from petroleum reservoirs is mainly composed of methane $\left(\mathrm{CH}_{4}\right)$, ethane $\left(\mathrm{C}_{2} \mathrm{H}_{6}\right)$, nitrogen $\left(\mathrm{N}_{2}\right)$, hydrogen $\left(\mathrm{H}_{2}\right)$, mercury $\left(\mathrm{H}_{\mathrm{g}}\right)$, ammonia $\left(\mathrm{NH}_{3}\right)$, hydrogen sulfide $\left(\mathrm{H}_{2} \mathrm{~S}\right)$, carbon dioxide $\left(\mathrm{CO}_{2}\right)$ and trace elements [26]. These trace elements along with acid gases represents contaminants in the natural gas, and could cause significant threat to the surface integrity of processing facilities.
Related issues include corrosion of vessel equipments, which is very expensive to deal with, making the project cost-intensive if not mitigated and prevented [15, 21].

The presence of corrosive substances such as hydrogen sulfide, carbon dioxide and/or mercaptan in the natural gas stream leads to the occurrences of electrochemical corrosion on the exposed metal surfaces [21]. The need to adequately remove these contaminants is of key interest to the petroleum mid-stream industry, petrochemical

Chukwugozie Jekwu Ejeh, echukwugozie@gmail.com; Goh Prince-Henry Mawufemor, proincegoh90@gmail.com; Annan Ransford, paakwasiramzy@gmail.com | ${ }^{1}$ Oil and Gas Engineering Department, School of Engineering, All Nations University College, P.O Box KF1908 ER, Koforidua, Ghana. 
industry and process industry to enhance the commercial value of the natural gas. Among these contaminants, hydrogen sulfide and carbon dioxide possess a greater concern. Therefore, this paper focuses on removing these contaminants from the feed [1]. The process of using chemical or physical solvents to remove these gases from the raw gas feed is referred to as natural gas sweetening, and its key focus is to meet the sales gas specification [1, $11]$.

In the modeling and simulation of acid gas removal using absorption and desorption columns with solvents where chemical reactions occur, three fundamental methods can be implemented [6]. These are equilibrium, non-equilibrium and mass transfer models. With the equilibrium method, a tray is used in the absorber column to serve as an equilibrium stage such that the output flow current is in a state of equilibrium with each other. Here, the actual number of trays in the column is calculated using the tray coefficient efficiency which was reported to vary between 0.1 and 0.4 over the column. Due to the relatively small tray efficiency values, the calculation output is very sensitive to slight alterations in the efficiency coefficient [24]. However, currently no precise approach for estimating the tray coefficient has been proposed. The dependency of its calculation on the hydrodynamic, chemical reaction rate and liquid and gas composition in the tray makes it difficult to postulate an accurate method of the tray efficiency coefficient.

With the non-equilibrium model, the equilibrium is applicable at the two-phase interface, and the mass and energy balance equations for each component in each phase are solved simultaneously. The application of this approach requires hydraulic column considerations, and it is possible to calculate the pressure changes in the absorber column during the absorption and desorption processes of the acid gases from the natural gas. In addition, in software such as CHEMCAD, ChemSep and RATEFRAC of Aspen Plus software, this approach is used for the design of the absorption column [24].

Finally, the third model is technically referred to as the mass transfer model [9]. When used, each tray is considered as a contact stage to model gas- and liquid-phase mass transfer. In the process, the gas and liquid phases flow into the input tray, and as a result of its peculiar form of mass insoles (froth), high-level contact with gas and liquid is being treated which therefore yields mass transfer between the two phases. Being able to calculate the amount or rate of mass transfer in this froth makes it possible to provide a reliable estimation of the concentration of the outlet flow. Based on this concept, components will readily diffuse from the bulk gas to gas interface and further transfer to the liquid interface. Hence, the use of tray efficiency coefficient is not required and the actual number of trays can be determined directly using the mass transfer method [24].

In most industrial applications, chemical and/or physical solvents are used to effectively improve the percentage composition of methane in the natural gas stream. In most cases, chemical and physical solvents are blended together for this purpose [22]. The commonly used secondary amines for acid gas removal are methyl di-ethyl amine (MDEA), di-glycol amine (DGA) and di-iso-propanol amine (DIPA). These chemical solvents have been shown to be promising during their application. Khan et al. [17] investigated high-pressure solubility of carbon dioxide $\left(\mathrm{CO}_{2}\right)$ in an aqueous solution of piperazine (PZ)-activated $\mathrm{N}$-methyldiethanolamine (MDEA) solvent for $\mathrm{CO}_{2}$ capture. It was found that the absorption efficiency of the amine chemical to $\mathrm{CO}_{2}$ content was high at lower temperatures. Sarker [23] also conducted the research on blending different primary amines and considered the effect of temperature, concentration, circulation rate and number of stages to the gas sweetening process performance. In his study, the secondary amines were blended to form DGA-MEA, DEA-MDEA, DIPA and sulfolane -MDEA. Results showed that the percentage increase in the methane content decreased with increasing operating temperature and likewise pressure. In addition, the acid gas content increased with higher operating temperatures with the application of sulfolane-MDEA solvent [13]. Figure 1 shows the structural formula of various primary, secondary and tertiary alkanolamines used for blending with a physical solvent to produce a hybrid solution with an enhanced reaction kinetics and solubility to acid gases in the natural gas.

Physical solvents such as dimethyl ether-polyethylene glycol (DEPG), $\mathrm{N}$-methyl-2-pyrrolidone (NMP), methanol $\left(\mathrm{CH}_{3} \mathrm{OH}\right)$ and propylene carbonate $(\mathrm{PC})$ are becoming increasingly popular as gas treating solvents, especially for coal gasification applications [5, 8]. Natural gas streams with high acid gas or impurities content (above 16\%), using physical solvents is preferred than chemical solvents due to a reduced solvent regeneration energy, high acid gas absorption, partial dehydration of the feed gas ability and low-heat requirement [5]. In addition, physical solvents effectively strip-off acid gases from raw natural gas feed at low pressure and heat [5].

However, a novel approach has been developed to improve the performance of sulfolane solvent. The enhancement was based on blending sulfolane with a secondary amine to yield Sulfinol chemical [4]. Sulfinol is a solvent that combines the advantage of using both chemical and physical solvents. It is preferred than using only physical or chemical solvents on its own [4]. The solvent contains sulfolane, water, DIPA or MDEA. The process of using Sulfinol for the removal of $\mathrm{H}_{2} \mathrm{~S}, \mathrm{CO}_{2}, \mathrm{COS}$ and mercaptan from raw natural gas is termed the Shell process [4]. 


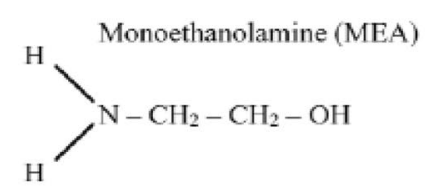

Diethanolamine (DEA)<smiles>OCCCCCCCO</smiles>

Triethanolamine (TEA)<smiles>OCCCN(CCO)CCO</smiles>
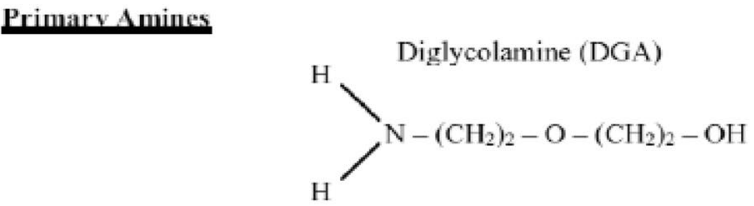

Secondary Amines

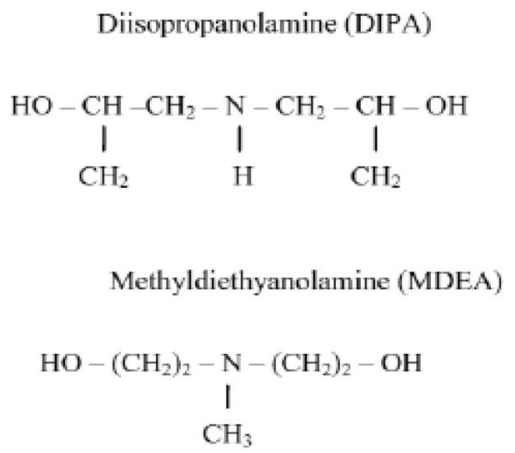

Fig. 1 Various primary, secondary and tertiary alkanolamines [18]

Key advantages of this method over chemical and physical solvents are its relatively high solubility to acid gases, low energy requirement for regeneration, easily meets severe sales specification and relatively low co-absorption of the gaseous hydrocarbons. Its performance makes it a suitable sweetening solvent of reagent for liquefied natural gas (LNG) processing [10, 20].

Ghanbarabadi and Khoshandam [11] used sulfolane and MDEA blend in llam gas refinery for natural gas processing, to meet sales gas specifications. It was found that $30-40 \%$ mercaptan along with hydrogen sulphide and carbondioxide, requiring less than $25 \%$ regeneration energy, compared to using MDEA as a standalone solvent. This value is relatively low when compared to standards for sales gas globally, implying that an alternative approach is required to enhance the performance of the solvent.

This paper seeks to address the problem related to enhanced removal process of hydrogen sulfide and carbon dioxide in the natural gas feed and issues related to solvent regeneration when using traditional amine chemicals, stripping of methane along with the acid gas and meeting the sales gas specification. The Shell process solvent (sulfolane-DIPA blend) better addresses this problem. The performance of the proposed solvent is dependent on its solubility to the acid gas, regeneration rate, dehydration capacity and reduction in methane absorption.

Many techniques have been developed to enhance natural gas sweetening process performance. For instance, Hao et al. [14] used an ionic liquid/ZIF-8 mixed matrix membranes at room temperature, Kumar et al. [19] developed a technology named ionic liquid-amine blends and CO2BOLs for the same objective, and Adib et al. [2] published a research on the use of support vector machine-based modeling of an industrial natural gas sweetening plant to optimize its acid gas removal efficiency. It is clear that the application of these innovative approaches failed to consider the effect of operating temperatures and pressures to the gas sweetening process performance. Moreover, limited or no work was considered using an optimized form of physical and chemical solvent formulation called the Shell process for natural sweetening process, and an entirely different approach was considered in this paper. Successful achievement of the research will provide knowledge about optimum sulfolane-DIPA blend and its most suitable operating temperature and pressure to process raw natural gas with the aim of meeting sales gas specification.

\section{Process description}

The natural gas feed used contained $16.9 \%$ acid gases. Aspen HYSYS software was used in this study as the analytical tool to model and simulate gas sweetening process with the sole aim of effectively minimizing $\mathrm{H}_{2} \mathrm{~S}$ and $\mathrm{CO}_{2}$ in the natural gas feed. A review of the literature established that the Shell process solvent formulation obtained from blending sulfolane and DIPA is highly recommended for this purpose. As a part of the aim of this work, a sensitivity study is conducted to ascertain the suitable blending ratio for an improved acid gas removal performance. In the formulation of the gas sweetening solvent, $15 \%$ water was added in the blending stream to enhance the chemical reaction of the lean solvent mixture components. The 
target was to determine the suitable Sulfonil-DIPA solvent blend ratio and operating condition (temperature and pressure) to $\mathrm{H}_{2} \mathrm{~S}$ and $\mathrm{CO}_{2}$ removal and an increase in methane content to meet sales gas specifications.

The process flow sheet or model used for the study is shown in Fig. 2a. The data presented on the dashboard were used for the initial case analysis. In contrast, Fig. 2a also shows the temperature control dashboard, make-up block, amine pump, amine cooler and recycling control panel. The connecting lines linking the different components were differentiated with colors. These colors represent the temperature of the substance in the flow line or stream temperature. These colors and the corresponding temperature ranges are identified in the temperature dashboard. The raw gas data and lean amine properties shown in Tables 1 and 2, respectively, were obtained from

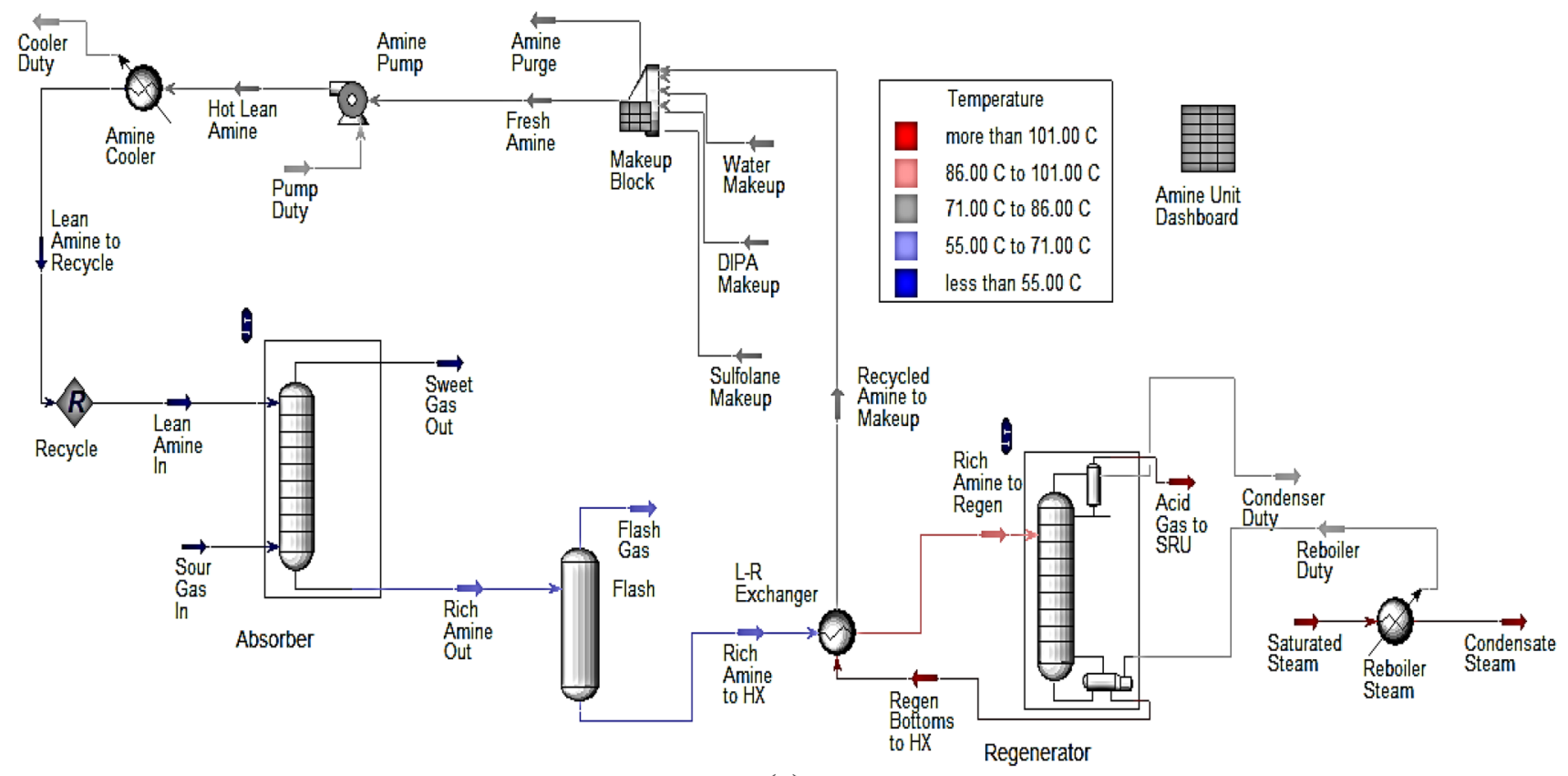

(a)

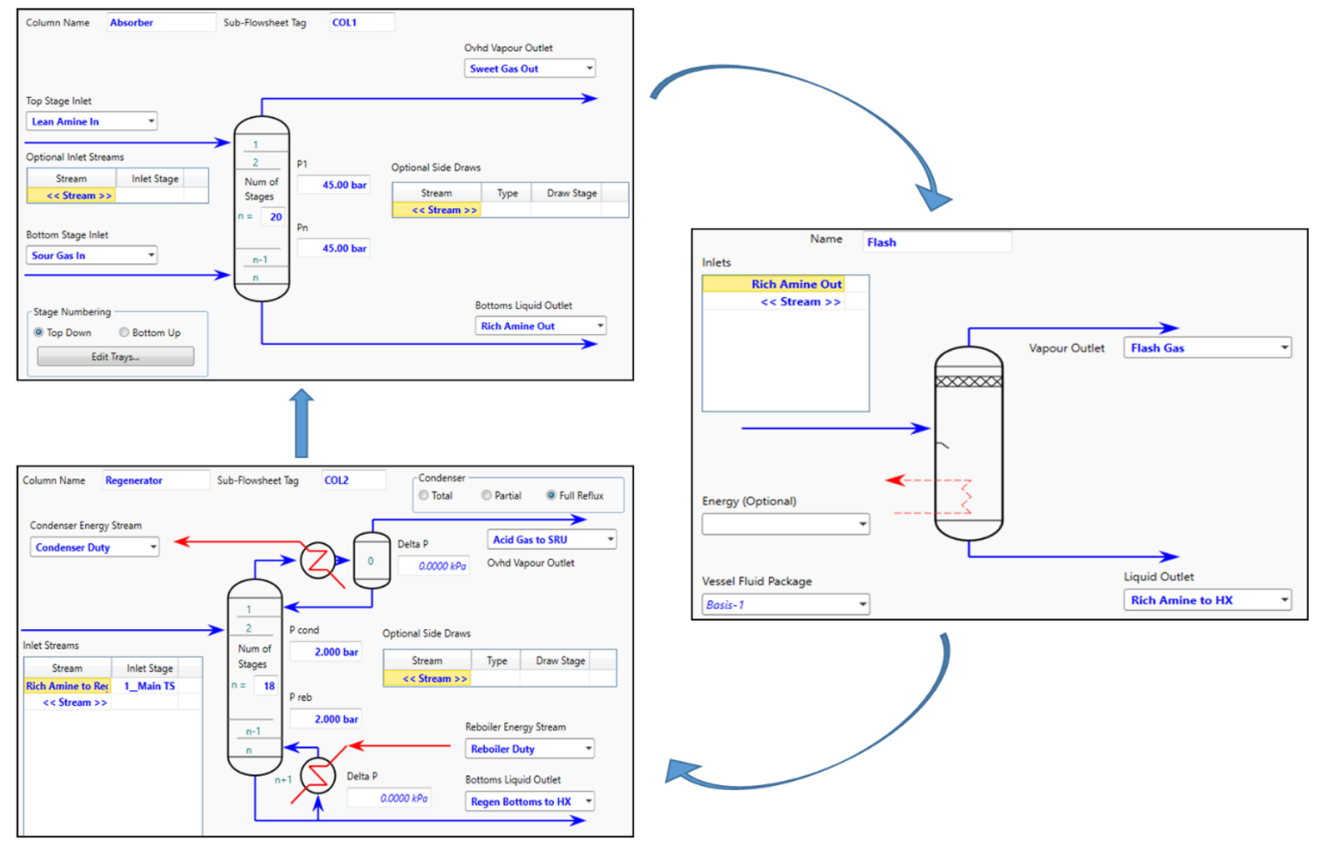

(b)

Fig. 2 a Natural gas sweetening flow process sheet. b Description of column internal schematics 
Table 1 Raw gas feed properties

\begin{tabular}{ll}
\hline Material stream & Mole fraction \\
\hline Carbon dioxide & 0.094 \\
Hydrogen sulfide & 0.075 \\
Methane & 0.800 \\
Ethane & 0.010 \\
Propane & 0.000 \\
Nitrogen & 0.020 \\
Water content & 0.001 \\
\hline
\end{tabular}

Table 2 Chemical and physical properties of lean amine

\begin{tabular}{ll}
\hline Stream name & Data \\
\hline Molecular weight & 66.5 \\
Molar density (lbmole/ft ${ }^{3}$ ) & 1.0 \\
Mass density (lb/ft ${ }^{3}$ ) & 67.9 \\
Mass enthalpy (Btu/lb) & -2450.4 \\
Mass entropy (Btu/lb-F) & -1.6 \\
Heat capacity (Btu/lbmole-F) & 48.6 \\
LHV molar basis (Std) (Btu/lbmole) & $587,670.4$ \\
HHV molar basis (Std) (Btu/lbmole) & $642,771.5$ \\
CO ${ }_{2}$ loading & $1.8 \mathrm{e}-004$ \\
CO ${ }_{2}$ apparent mole conc $\left(\mathrm{lbmole} / \mathrm{ft}^{3}\right.$ ) & $8.3 \mathrm{e}-005$ \\
CO ${ }_{2}$ apparent wt. conc (lbmol//lb) & $1.2 \mathrm{e}-006$ \\
Mass exergy (Btu/lb) & 3.1 \\
Specific heat (Btu/lbmole-F) & 48.6 \\
Z factor & 0.1 \\
Watson K & 8.9 \\
Cp/(Cp-R) & 1.1 \\
Cp/Cv & 2.4 \\
Kinematic viscosity (cSt) & 11.9 \\
Liq. mass density (Std. Cond) (lb/ft ${ }^{3}$ ) & 69.3 \\
Liq. vol. flow (Std. Cond) (m ${ }^{3} / \mathrm{h}$ ) & 819.5 \\
Liquid fraction & 1.0 \\
Molar volume (ft $\left.{ }^{3} / \mathrm{lbmole}\right)$ & 1.0 \\
Surface tension (dyne/cm) & 39.4 \\
Thermal conductivity (Btu/hr-ft-F) & 0.1 \\
Viscosity (cP) & 12.9 \\
Cv (Btu/lbmole-F) & 20.7 \\
Mass Cv (Btu/lb-F) & 0.3 \\
Viscosity index & 24.6 \\
Bubble point pressure (bar) & $7.8 \mathrm{e}-002$ \\
\hline
\end{tabular}

Aspen HYSYS v. 10 component data library. However, the feed gas stream data were modified to suit the case study.

The lean amine introduced into the absorber column was obtained from blending the physical solvent, chemical solvent and water. The blending process of these components was performed using a make-up block. The makeup block provided room to vary the component mixture proportion. The initial component proportion was $15 \%$ water, $40 \%$ sulfolane and $45 \%$ DIPA to form fresh lean solution. The temperature and pressure in the make-up block were $76.46{ }^{\circ} \mathrm{C}$ and $2.0 \mathrm{bar}$, respectively. The fresh lean solvent was set to flow at a rate of $819.5 \mathrm{~m}^{3} / \mathrm{h}$ toward the amine pump for re-pressurization. At this stage, the flow pressure of the lean solvent was increased to $45.5 \mathrm{bar}$ using the amine pump. Since temperature and pressure varied linearly with each other, an increase in the solvent pressure will cause the solution temperature to increase relatively. A total $1370 \mathrm{KW}$ pump duty was applied to ensure the effective flow of the solvent.

The hot lean solvent extracted from the amine pump was cooled to a desired process set temperature of $50{ }^{\circ} \mathrm{C}$ using the amine cooler while maintaining the pressure at 45.5 bar. A $21,100 \mathrm{KW}$ electrical energy or power was applied to cool the hot amine and was found to be exceed the pump duty. It was found that the cooling process required $21,100 \mathrm{~kW}$ of electrical energy to reduce the stream temperature by an amount $37.04{ }^{\circ} \mathrm{C}$ while maintaining the flow pressure at 45.5 bar. This process was done to meet required refinery process standard. As a result, the lean amine line was connected to a recycler device to control the inlet flow rate of the solvent into the absorber feed, where the raw gas interacts chemically with the solvent.

The absorption column was designed to have 20 trays or stages. This selection is hypothetical. The pressure at all stages was maintained at 45 bar. It was observed that the temperature of the mixture increased nonlinearly with an increasing number of stages downward. The stages or trays were numbered from top to bottom sequentially. The tower sizing data are given in Table 3 . Also, the relationship between the acid gas composition versus trays from the top and corresponding temperature at each stage number is shown in Fig. $3 a$ and b, respectively.

The raw gas was fed from the bottom at $40{ }^{\circ} \mathrm{C}$ with a mass flow rate of $79 \mathrm{~kg} / \mathrm{s}$. The lean amine or solvent was introduced from the top of the column and flowed downward. As a result of gravity, the gas moved upward and made multiple contacts with the lean amine

Table 3 Absorber column design description

\begin{tabular}{ll}
\hline Tower & TS-1 \\
\hline Uniform section & Equal \\
Internal type & Valve \\
Diameter $(\mathrm{m})$ & 4.000 \\
Tray/packed space $(\mathrm{m})$ & 0.700 \\
Tray/packed volume $\left(\mathrm{m}^{3}\right)$ & 8.797 \\
Holdup rate & 0.733 \\
Weeping factor & 1.000 \\
Number of trays & 20 \\
\hline
\end{tabular}


Composition vs. Tray Position from Top

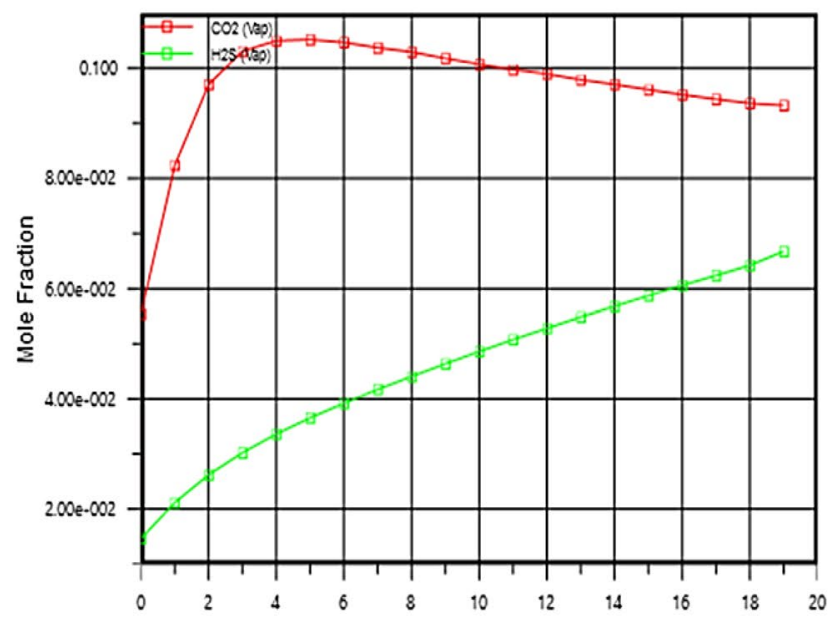

(a)
Temperature vs. Tray Position from Top

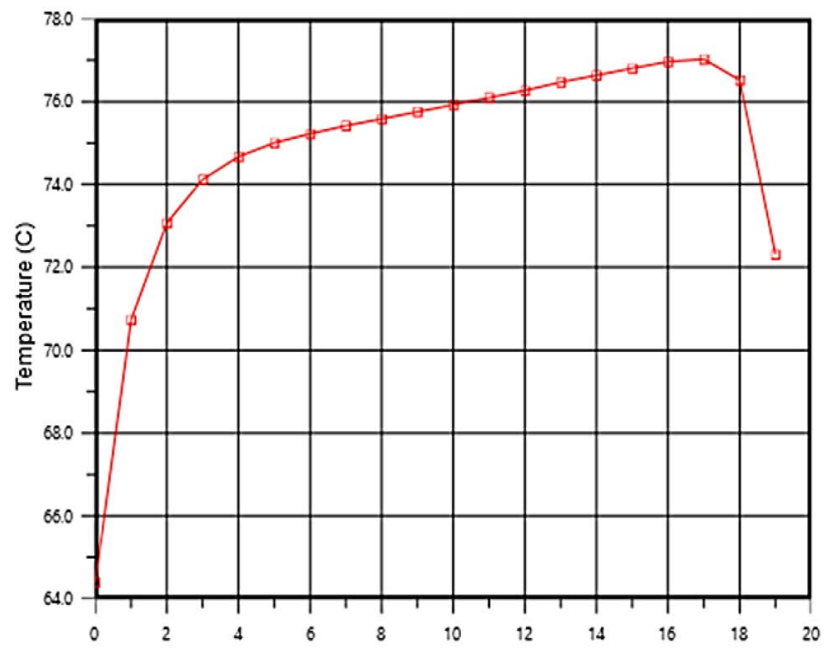

(b)

Fig. 3 a Acid gas composition and $\mathbf{b}$ temperature versus tray position from the top of the absorber column

solution. Due to the mixing process of the raw gas and lean solvent, hydrogen sulfide and carbon dioxide are absorbed to yield a gas stream with little or no acid gases. The sweet gas was extracted from the top of the absorber column, while the rich amine solvent containing the absorbed acid gases was derived from the bottom of the column for regeneration.

The solvent rich with $\mathrm{H}_{2} \mathrm{~S}$ and $\mathrm{CO}_{2}$ was extracted from the bottom of the absorber and sent for further processing, to be treated and recycled, so as to repeat the sweetening process. The acid gas was then transmitted to the sulfur recovery unit (SRU) and condenses to liquid for disposal or further processing. This is shown in Fig. 1.

Figure $2 \mathrm{~b}$ describes the internal schematics or settings for the reformer, flash and regenerator column arranged in the operational cycle and how the various equilibrium, non-equilibrium and mass transfer processes through the columns interact to ensure a continuous natural gas sweetening process.

Figure $3 \mathrm{a}$ and $\mathrm{b}$ demonstrates acid gas composition in mole fraction at different tray positions in the absorber column and temperature at different trays from the top to the bottom of the column. This plot was generated at the initial process condition. It is observed that the temperature variation of the trays is not linear. However, it is observed to be high at stages 10-18, where maximum contact between the solvent and the sour gas is experienced. As a result, the acid gas mole fraction is influenced by the chemical process.

\subsection{Absorption mechanism of $\mathrm{H}_{2} \mathrm{~S}$ and $\mathrm{CO}_{2}$ in the absorber}

The principal reaction occurring between $\mathrm{H}_{2} \mathrm{~S}$ and $\mathrm{CO}_{2}$, and the secondary amine in the absorber column is demonstrated as follows:

$\mathrm{H}_{2} \mathrm{O} \leftrightarrow \mathrm{H}^{+}+\mathrm{OH}^{-}$

$\mathrm{R}_{1} \mathrm{R}_{2} \mathrm{NH}+\mathrm{H}^{+} \leftrightarrow \mathrm{R}_{1} \mathrm{R}_{2} \mathrm{NH}_{2}^{+}$

$\mathrm{H}_{2} \mathrm{~S} \leftrightarrow \mathrm{H}^{+}+\mathrm{HS}^{-}$

From reactions (1a-1c), aminehydrosophide formation is possible. With respect to $\mathrm{CO}_{2}$ absorption, two different reactive approaches are available. The first mechanism involves hydrolysis of $\mathrm{CO}_{2}$ to form bicarbonate ions which then react with the protonated ion in the absorber system. The chemical reaction is described in Eqs. (2a, 2b), and Eq. (3) describes the second reaction mechanism which occurs only if a hydrogen ion is present in the amine structure and forms carbamate. This product further reacts with another amine compound to form amine salt.

$\mathrm{CO}_{2}+\mathrm{H}_{2} \mathrm{O} \leftrightarrow \mathrm{H}^{+}+\mathrm{HCO}_{3}^{-}$

$\mathrm{R}_{1} \mathrm{R}_{2} \mathrm{NH}_{2}^{+}+\mathrm{HCO}_{3}^{-} \leftrightarrow \mathrm{R}_{1} \mathrm{R}_{2} \mathrm{NH}_{2}^{+} \mathrm{HCO}_{3}^{-}$ 
$\mathrm{R}_{1} \mathrm{R}_{2} \mathrm{NH}+\mathrm{CO}_{2} \leftrightarrow \mathrm{R}_{1} \mathrm{R}_{2} \mathrm{NCOO}^{-}+\mathrm{H}^{+}$

With connection to the process reaction described in Fig. $2 a$, the end product from the subreactions $(1 \mathrm{a}-1 \mathrm{c})$ and $(2 a, 2 b)$ is defined using the term rich amine as shown in the bottom absorber extract. The bottom extracted amine is rich with the acid gas from the feed and sent to the flash column for separation and further sent to the regenerator column for lean amine generation.

\section{Results and discussion}

This section provides a detail description of the results obtained from flow process. Section 3.1 focuses on investigating the effect of additive strength in water for a single component to $\mathrm{H}_{2} \mathrm{~S}$ and $\mathrm{CO}_{2}$ removal. That is, water is added to sulfolane solution only. The target is to evaluate the impact of the sulfolane solvent only to acid gas removal, before considering the addition of other components to form the sweetening reagent. Moreover, Sect. 3.2 determines the suitable operating temperature and pressure for an improved natural gas sweetening performance of the solvent. At each stage, the most suitable operating information is derived and applied in the subsequent analysis. However, the results obtained will be validated with the published data, to ascertain the reliability of the process model design.

\subsection{Effect of additive strength to acid gas removal}

The additive strength is a measure of the percentage composition of the solute in the sweetening fluid. In this case, sulfolane and water were mixed together to form a solution, excluding the addition of the secondary alkanolamine (DIPA). The idea behind these is to evaluate the effectiveness of the physical solvent to $\mathrm{H}_{2} \mathrm{~S}$ and $\mathrm{CO}_{2}$ removal. The strength of the additive was increased sequentially and its effect was recorded at the end of the simulation run.

The plot in Fig. 4 shows the relationship between the additive strength, and $\mathrm{H}_{2} \mathrm{~S}$ and $\mathrm{CO}_{2}$ contents in the natural gas feed. It was observed that an increase in the sulfolane strength contributed to a nonlinear decrease in the $\mathrm{H}_{2} \mathrm{~S}$ and $\mathrm{CO}_{2}$ composition. This was so because the sulfolane has higher solubility to the acid gas than to water. However, the sales gas specification was not met. According to the American Petroleum Institute (API), the acid gas content in the natural gas should be less than $4.0 \mathrm{ppm} \mathrm{H}_{2} \mathrm{~S}$ and $2.0 \mathrm{~mol} \% \mathrm{CO}_{2}$ content.

The bar-chart in Fig. $5 \mathrm{a}$ and $\mathrm{b}$ shows the discrete relationship between $\mathrm{H}_{2} \mathrm{~S}$ and $\mathrm{CO}_{2}$ removal, respectively, for each blend design. It should be noted that the blend

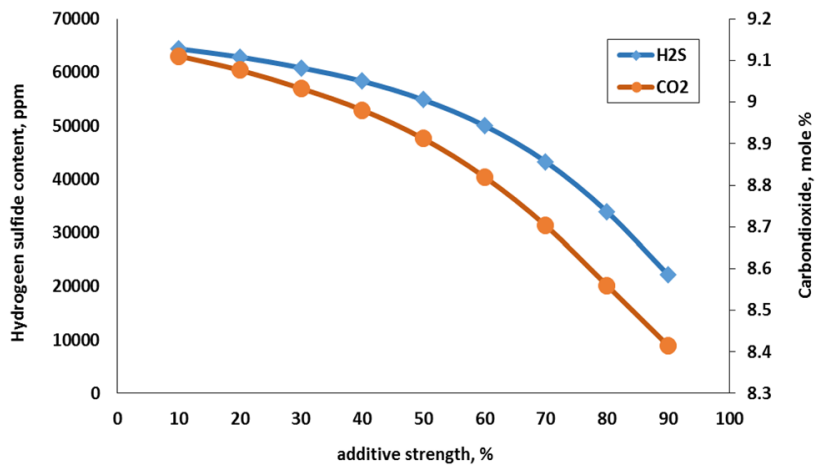

Fig. 4 Effect of sulfolane strength to acid gas removal

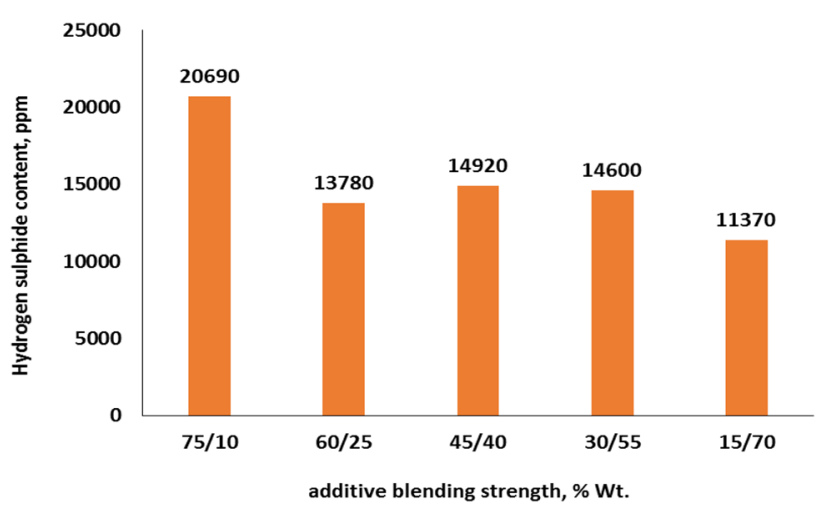

(a)

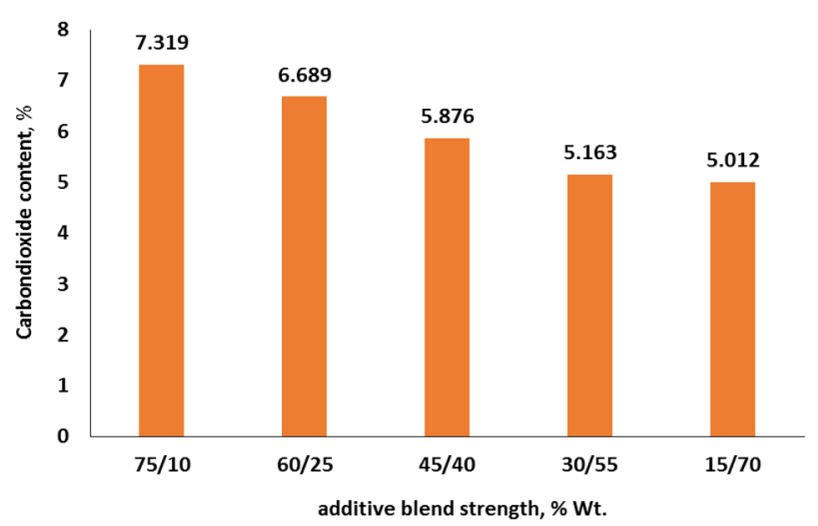

(b)

Fig. 5 Effect of additive blend strength on a hydrogen sulfide and b carbon dioxide acid gas removal

design $75 / 10$ is interpreted as $15 \%$ water, $75 \%$ sulfolane and $10 \%$ DIPA. Note that the water content in the solvent was kept constant, while the additive strength was varied to evaluate its influence.

Comparing the results obtained in Fig. $5 a$ and b, it is obvious that an increase in the composition of DIPA chemical in the Sulfonil solvent formulation contributed significantly to enhancing the acid gas removal performance. 
Therefore, the $\mathrm{H}_{2} \mathrm{~S}$ and $\mathrm{CO}_{2}$ absorption efficiency of the Sulfonil process was enhanced after adding DIPA chemical. However, adding DIPA chemical above the limit $70-80 \%$ will decrease the regeneration rate of the chemical solvent and the tendency for the physical solvent to absorb the acid gas without initiating further chemical reaction, to ease flash out of the rich amine by reducing the pressure.

From detailed analysis, the blend design 15/70 achieved the best $\mathrm{H}_{2} \mathrm{~S}$ and $\mathrm{CO}_{2}$ acid gas removal performance. The reduction in the $\mathrm{H}_{2} \mathrm{~S}$ and $\mathrm{CO}_{2}$ content of the natural gas feed obtained at this stage was $11,370 \mathrm{ppm}$ and $5.012 \mathrm{~mol} \%$, respectively. These values are significant and show that the percentage reduction in the $\mathrm{H}_{2} \mathrm{~S}$ and $\mathrm{CO}_{2}$ obtained from the process so far is 84.84 and 43.88 , respectively. Despite the strategic formulation, sales gas benchmark was not met. The initial values of the acid gas content in the raw gas stream are given in Table 1. In addition, the process was conducted at temperature and pressure of $50{ }^{\circ} \mathrm{C}$ and 45.5 bar, respectively, and a flow rate of $819.5 \mathrm{~m}^{3} / \mathrm{h}$, as it represents an average of the standard operating conditions in a typical refinery process and also for analytic purpose.

Since the target was not met, it was necessary to look into the effect of operating conditions to the Sulfonil process performance. The lean amine temperature and pressure were considered to be the objective function for the further analysis.

\subsection{Determination of suitable operating condition}

The determination of the most suitable operating conditions lies in the application of temperature and pressure and others. This study was limited to using temperature and pressure as the parametric functions, from which a conclusion about the suitable operating temperature and pressure can be drawn. The Sulfonil process formulation used in this analysis was $15 \%$ water, $15 \%$ sulfolane and 70 DIPA. This blend formulation was obtained from the analysis performed in Sect. 3.1, because it yielded the best acid gas removal performance compared to others.

\subsubsection{Effect of lean amine temperature}

Due to the exothermic characteristics between the solvent and acid gases in the absorber column, loss of heat is expected where the sweet gas is extracted from the top of the column at higher temperatures. To compensate for the loss, heat energy is required. This can be achieved by increasing the temperature of the gradient at the contact tower. Studies show that for an improved absorption efficiency at the contact interface of both phases, it is necessary to ensure that the temperature gradient is sufficiently high [16]. By so doing, the lean amine temperature was varied from 5 to $210^{\circ} \mathrm{C}$. The range is hypothetical for analytic purpose, and the process was carried out at a pressure of 45.5 bar and $819.5 \mathrm{~m}^{3} / \mathrm{h}$ molar flow rate of the lean amine in the absorber column.

From a critical observation of the results shown in Fig. $6 a$ and $b$, lower levels of hydrogen sulfide and carbon dioxide concentrations were obtained at lower operating temperatures of the lean amine below $15^{\circ} \mathrm{C}$. At this condition, the temperature gradient was sufficiently high to enable efficient absorption process of the acid gases from the natural gas. Vahidi et al. [25] in their publication with Energy Reports Journal achieved the same findings. At the end of this study, the $\mathrm{H}_{2} \mathrm{~S}$ and $\mathrm{CO}_{2}$ content in the sweet gas stream was $5.1 \mathrm{ppm}$ and $0.3207 \mathrm{~mol} \%$, respectively.

The result was validated with results obtained by Jas$\operatorname{sim}[16]$. He focused his work on the selective removal of hydrogen sulfide from the sour gas, in the presence of carbon dioxide using MDEA (15-50 wt\%). Also, the effect of lean amine temperature was investigated in the normalized interval of $25-162{ }^{\circ} \mathrm{C}$ and used to validate the result obtained in Fig. $6 a$ and b. Therefore, it shows that the performance of the gas sweetening agent solvent is enhanced as lower operating temperatures. The comparative plot is shown in Fig. 6a and b.

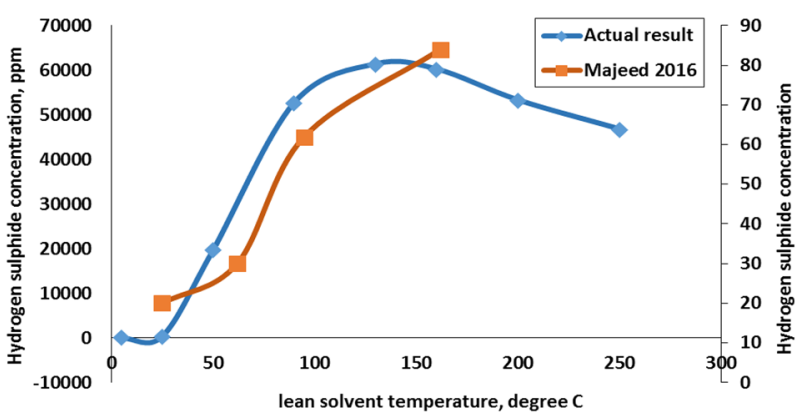

(a)

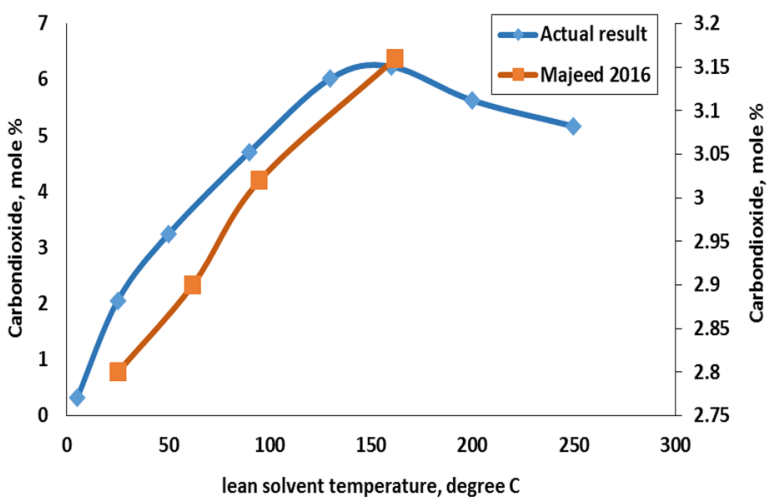

(b)

Fig. 6 a Effect of lean solvent temperature on hydrogen sulfide removal. $\mathbf{b}$ Effect of lean solvent temperature on carbon dioxide removal 


\subsubsection{Effect of lean amine pressure}

The operating conditions in Sect. 3.2.1 were the same for this study with the exception of the lean amine temperature. From the previous analysis, it was observed that at lower temperatures, the Sulfonil-X process formulation obtained a suitable $\mathrm{H}_{2} \mathrm{~S}$ and $\mathrm{CO}_{2}$ removal performance. The lean amine pressure then varied between 5 and 300 bar while maintaining the temperature at the recommended value. Based on the ideal gas law, the temperature and pressure of a fluid vary linearly, assuming a constant volume. This was true in this analysis. The plot in Fig. 7 shows that a suitable percentage content of the $\mathrm{H}_{2} \mathrm{~S}$ and $\mathrm{CO}_{2}$ gases was obtained at lower pressures and hence agrees well with theoretical laws and literature. At lower pressure, the injected solvent gains enough time to absorb additional acid gas concentrations from the gas feed, compared to a higher pressure.

\subsection{Sweet gas composition analysis}

Recall from Sect. 2.1, Table 1 provides a detail composition of the sour gas stream. The raw gas was classified as sour because of high sulfur content irrespective of the relatively high $\mathrm{CO}_{2}$ percentage composition in the raw gas beyond the sales gas specification. However, to obtain a sweet gas stream, the percentage composition of the acid gases most especially hydrogen sulfide is to be minimized efficiently.

The plot in Figs. 8 and 9 demonstrates hydrocarbon recovery and contaminant removal, respectively. These plots were generated to provide a comparative description of the efficiency of the Sulfonil-X acid gas removal

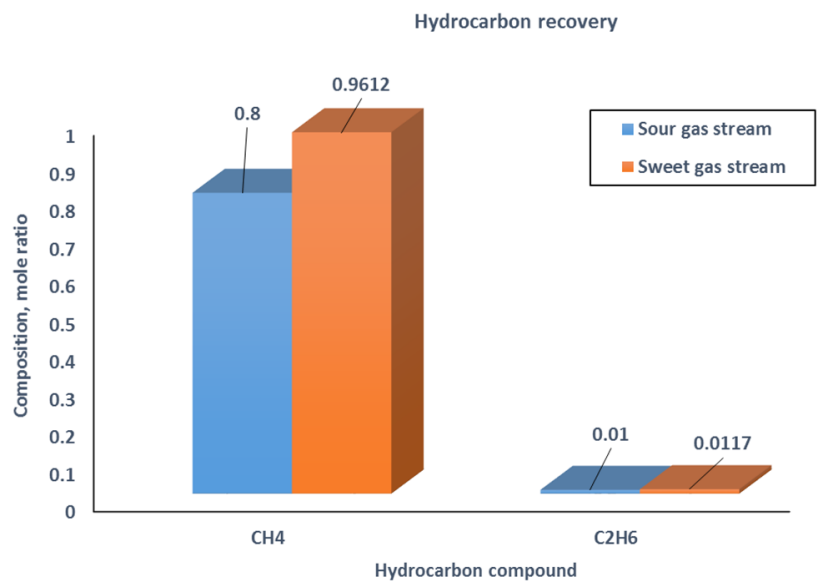

Fig. 8 Comparative plot showing methane and ethane recovery

efficiency, while considering temperature and pressure effect.

The application of the solvent at specific operating temperature and pressure increased the methane content by an amount 0.1612 , to yield $96.12 \%$ methane composition. This value is relatively high and shows that the sweet gas stream is rich with $96.12 \%$ methane. Further insight into the report shows that the sweet gas is dry and free from sulfur.

From Fig. 9, it was observed that the acid gas content in the raw gas was reduced significantly. Hydrogen sulfide content was observed to be approximately equal to zero, and carbon dioxide composition reduced from 9.4 to $0.26 \%$. Hence, it yielded a sweet gas stream. The nitrogen content was found to increase by $0.43 \%$. This value is minimal and can be eliminated by incorporating a nitrogen
Fig. 7 Effect of lean solvent flow pressure to acid gas removal

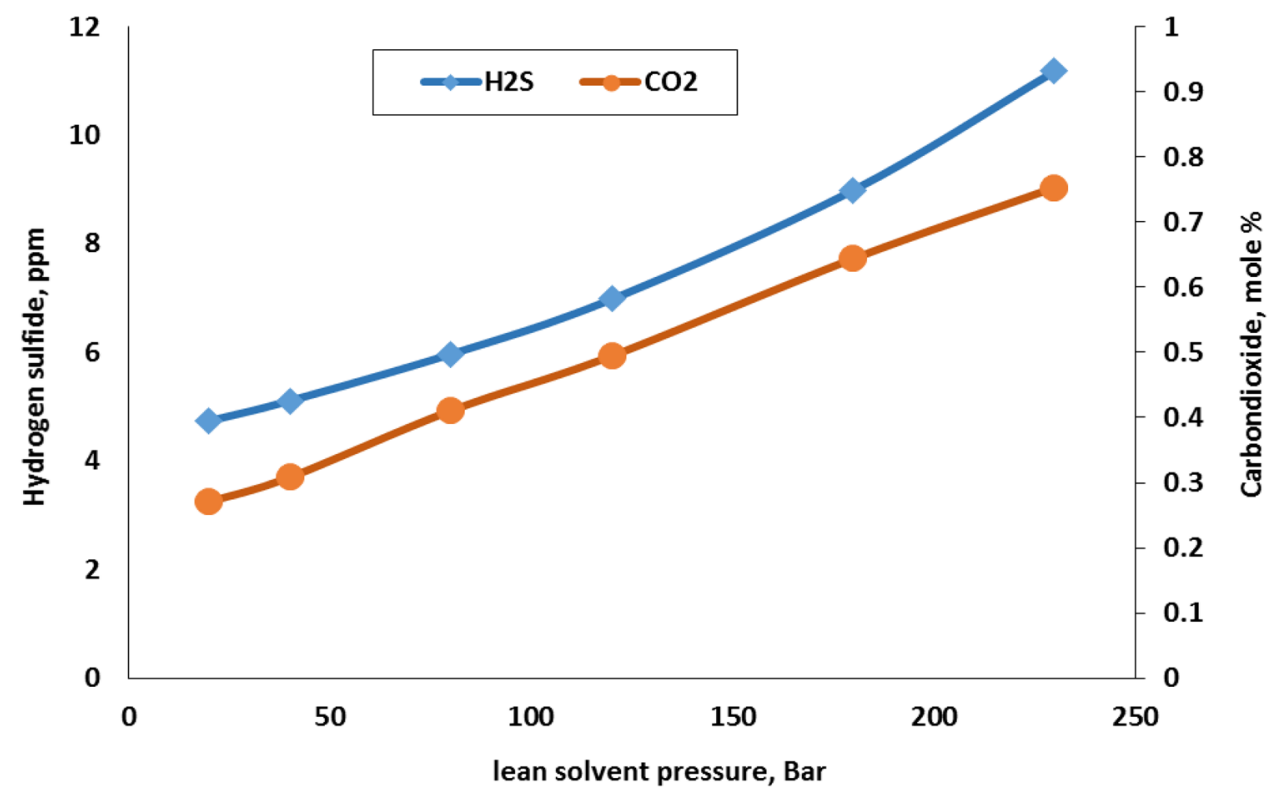

SN Applied Sciences 
Fig. 9 Comparative plot showing contaminants removal
Contaminants reduction

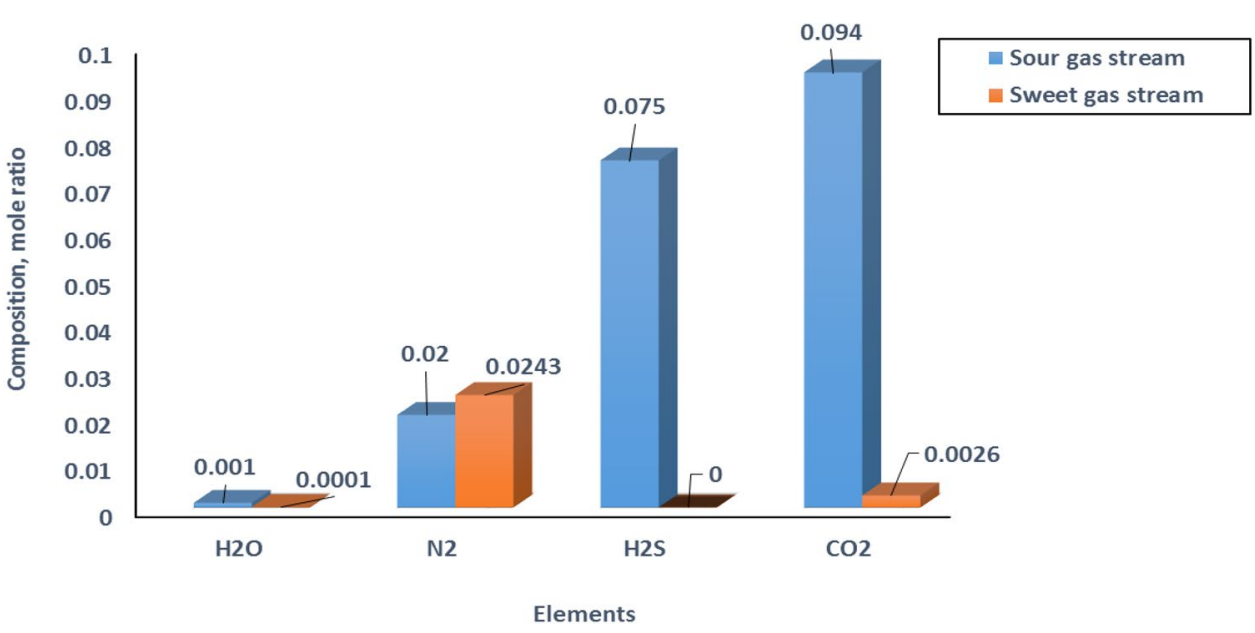

recovery unit in the process flow diagram. The nitrogen can be stripped and used for further processing with hydrogen, to form ammonia, which can be used for the production of fertilizers.

Despite the fact that $15 \%$ of water was added to the blend solution, the water content of the sweet gas stream was reduced by an amount of 0.0009 (90\%). The target of the solvent was to remove the acid gas; however, it further reduced the water content of the raw gas significantly. This was accounted by the dehydration ability of the DIPA chemical and hence produces a gas stream with relatively low water content. This achievement agrees well with conclusions made by CHIYODA Corporation Company with respect to the Shell process, Sulfonil-X.

\section{Summary of findings and conclusion}

From the research findings, it was concluded that the operating temperature and pressure had an influence on the acid gas removal performance of the Sulfonil-X solvent. The product of the processed raw gas met the sales gas specification with $96.12 \%$ methane, approximately $0 \%$ sulfur, $0.26 \%$ carbon dioxide, $0.0001 \%$ water and $2.43 \%$ nitrogen content. This target was achieved using $15 \%$ water, $15 \%$ sulfolane and $70 \%$ DIPA in the Sulfonil- $X$ formulation at operating temperatures and pressures $5^{\circ} \mathrm{C}$ and $20 \mathrm{bar}$, respectively.

Adding to the above, the co-absorption problem of methane during lean solvent extraction for re-circulation and relatively low acid gas removal performance commonly experienced when using sulfolane and MDEA blend was addressed and prevented.

Conclusively, sulfolane unlike other types of physical solvent had higher acid gas removal ability for relatively higher partial pressures and low operating conditions, leading to better economy of the alkanolamine in the mixture, and higher solution loading of the Sulfonil process. The end point of these was an improved hydrogen sulfide and carbon dioxide removal which met the API sales gas specification. In line with Vahidi et al. [25] publication, the equilibrium solubility characteristics of the acid gas is high with secondary alkanolamines such as DIPA than tertiary types.

Nanoparticles combined with other chemicals have shown to provide great opportunities for a number of applications including enhanced oil recovery $[3,7,12]$. No work has considered using nanoparticles to speed up the absorption reaction of $\mathrm{H}_{2} \mathrm{~S}$ and $\mathrm{CO}_{2}$ from the natural gas stream, which could lead to higher regeneration rate of the amine solvent. We therefore recommend that an experimental study should be conducted using the Sulfonil process formulation as deduced from this paper with the addition of nanoparticles. This could improve the commercialization of the Sulfonil process as the recommended sweetening solvent to be used.

Acknowledgements We want to reference God for his amazing grace and All Nations University for providing the platform for which this research was successfully completed.

\section{Compliance with ethical standards}

Conflict of interest The authors declare that they have no conflict of interest.

\section{References}

1. Abdulrahman RK, Sebastine IM (2013) Natural gas sweetening process simulation and optimization: a case study of Khurmala field in Iraqi Kurdistan region. J Nat Gas Sci Eng 14:116-120 
2. Adib H, Sharifi F, Mehranbod N, Kazerooni NM, Koolivand M (2013) Support vector machine based modeling of an industrial natural gas sweetening plant. J Nat Gas Sci Eng 14:121-131

3. Almahfood M, Bai B (2018) The synergistic effects of nanoparticle-surfactant nanofluids in EOR applications. J Petrol Sci Eng 171:196-210

4. Bara JE, Flowers B, Mittenthal M (2019) The Board Of Trustees Of The University of Alabama. Reducing acid gases from streams. U.S. Patent Application $16 / 329,810$

5. Burr B, Lyddon L (2008) A comparison of physical solvents for acid gas removal. In: 87th annual gas processors association convention, Grapevine, TX, pp 2-5

6. Castrillon MC, Moura KO, Alves CA, Bastos-Neto M, Azevedo DC, Hofmann J, Möllmer J, Einicke WD, Gläser R (2016) $\mathrm{CO}_{2}$ and $\mathrm{H}_{2} \mathrm{~S}$ removal from $\mathrm{CH}_{4}$-rich streams by adsorption on activated carbons modified with $\mathrm{K}_{2} \mathrm{CO}_{3}, \mathrm{NaOH}$, or $\mathrm{Fe}_{2} \mathrm{O}_{3}$. Energy Fuels 30(11):9596-9604

7. Cheraghian $G$, Hendraningrat $L$ (2016) A review on applications of nanotechnology in the enhanced oil recovery part B: effects of nanoparticles on flooding. Int Nano Lett 6(1):1-10

8. Dave A, Pathak B, Dave M, Rezvani S, Huang Y, Hewitt N (2019) Process design of $\mathrm{CO}_{2}$ desorption from physical solvent dimethyl-ether of poly-ethylene-glycol. Mater Sci Energy Technol 3:209-217

9. Dehghani MR, Sahabi M, Shirvani M (2011) Modeling and simulation of absorption column of natural gas sweetening unit by mass transfer method

10. Dyment J, Watanasiri S (2015) Acid gas cleaning using DEPG physical solvents: validation with experimental and plant data. Aspen Technology Inc, Bedford

11. Ghanbarabadi H, Khoshandam B (2015) Simulation and comparison of Sulfinol solvent performance with Amine solvents in removing sulfur compounds and acid gases from natural sour gas. J Nat Gas Sci Eng 22:415-420

12. Guo F, He J, Johnson PA, Aryana SA (2017) Stabilization of $\mathrm{CO}_{2}$ foam using by-product fly ash and recyclable iron oxide nanoparticles to improve carbon utilization in EOR processes. Sustain Energy Fuels 1(4):814-822

13. Haghtalab A, Izadi A (2014) Simultaneous measurement solubility of carbon dioxide + hydrogen sulphide into aqueous blends of alkanolamines at high pressure. Fluid Phase Equilib 375:181-190

14. Hao L, Li P, Yang T, Chung TS (2013) Room temperature ionic liquid/ZIF-8 mixed-matrix membranes for natural gas sweetening and post-combustion $\mathrm{CO}_{2}$ capture. J Membr Sci 436:221-231

15. Jackson RB (2014) The integrity of oil and gas wells. Proc Natl Acad Sci 111(30):10902-10903
16. Jassim MS (2016) Sensitivity analyses and optimization of a gas sweetening plant for hydrogen sulfide and carbon dioxide capture using methyldiethanolamine solutions. J Nat Gas Sci Eng 36:175-183

17. Khan SN, Hailegiorgis SM, Man Z, Shariff AM (2017) High pressure solubility of carbon dioxide $\left(\mathrm{CO}_{2}\right)$ in aqueous solution of piperazine (PZ) activated $\mathrm{N}$-methyldiethanolamine (MDEA) solvent for $\mathrm{CO}_{2}$ capture. In: AIP conference proceedings, AIP Publishing. vol. 1891, no. 1, p 020081

18. Kidnay AJ, Parrish WR (2006) Fundamentals of natural gas processing. Taylor \& Francis Group, Boca Raton

19. Kumar S, Cho JH, Moon IL (2014) lonic liquid-amine blends and $\mathrm{CO}_{2} \mathrm{BOLs}$ : prospective solvents for natural gas sweetening and $\mathrm{CO}_{2}$ capture technology - a review. Int J Greenhouse Gas Control 20:87-116

20. Paxson AT, Yagüe JL, Varanasi KK, Gleason KK, Liu A (2017) Massachusetts Institute of Technology, 2017. Grafted Polymer Surfaces for Dropwise Condensation, and Associated Methods of Use and Manufacture. U.S. Patent Application 14/811,065

21. Popoola LT, Grema AS, Latinwo GK, Gutti B, Balogun AS (2013) Corrosion problems during oil and gas production and its mitigation. Int J Ind Chem 4(1):35

22. Rezakazemi M, Heydari I, Zhang Z (2017) Hybrid systems: combining membrane and absorption technologies leads to more efficient acid gases $\left(\mathrm{CO}_{2}\right.$ and $\left.\mathrm{H}_{2} \mathrm{~S}\right)$ removal from natural gas. $J$ CO2 Util 18:362-369

23. Sarker NK (2016) Theoretical effect of concentration, circulation rate, stages, pressure and temperature of single amine and amine mixture solvents on gas sweetening performance. Egypt J Petrol 25(3):343-354

24. Seader JD, Henley EJ (2006) Separation process principles, Chap. 12, 2nd edn. Wiley, Hoboken, p 12

25. Vahidi M, Zoghi AT, Moshtari B, Nonahal B (2013) Equilibrium solubility of carbon dioxide in an aqueous mixture of $\mathrm{N}$-methyldiethanolamine and diisopropanolamine: an experimental and modeling study. J Chem Eng Data 58(7):1963-1968

26. Vaughn JT, Koros WJ (2014) Analysis of feed stream acid gas concentration effects on the transport properties and separation performance of polymeric membranes for natural gas sweetening: a comparison between a glassy and rubbery polymer. J Membr Sci 465:107-116

Publisher's Note Springer Nature remains neutral with regard to jurisdictional claims in published maps and institutional affiliations. 